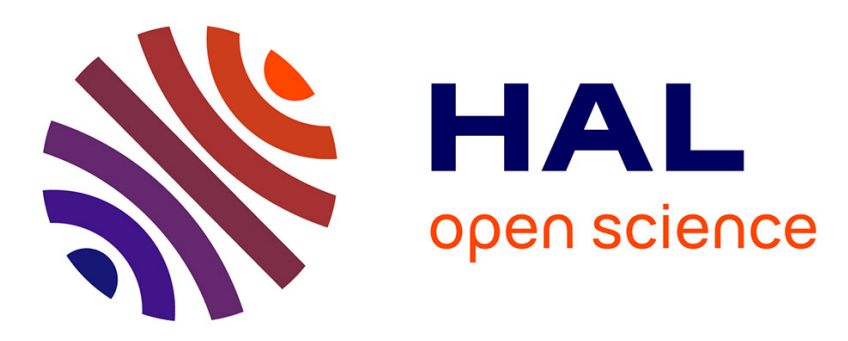

\title{
Combined Argumentation and Simulation to Support Decision
}

\author{
Rallou Thomopoulos, Bernard Moulin, Laurent Bedoussac
}

\section{To cite this version:}

Rallou Thomopoulos, Bernard Moulin, Laurent Bedoussac. Combined Argumentation and Simulation to Support Decision: Example to Assess the Attractiveness of a Change in Agriculture. IEA/AIE, Jun 2017, Arras, France. pp.275-281, 10.1007/978-3-319-60045-1_30 . lirmm-01580585

\section{HAL Id: lirmm-01580585 https://hal-lirmm.ccsd.cnrs.fr/lirmm-01580585}

Submitted on 1 Sep 2017

HAL is a multi-disciplinary open access archive for the deposit and dissemination of scientific research documents, whether they are published or not. The documents may come from teaching and research institutions in France or abroad, or from public or private research centers.
L'archive ouverte pluridisciplinaire HAL, est destinée au dépôt et à la diffusion de documents scientifiques de niveau recherche, publiés ou non, émanant des établissements d'enseignement et de recherche français ou étrangers, des laboratoires publics ou privés. 


\title{
Combined Argumentation and Simulation to Support Decision \\ Example to Assess the Attractiveness of a Change in Agriculture
}

\author{
Rallou Thomopoulos ${ }^{1(\bowtie)}$, Bernard Moulin ${ }^{2}$, and Laurent Bedoussac ${ }^{3}$ \\ 1 INRA UMR IATE/INRIA GraphIK, Montpellier, France \\ rallou.thomopoulos@inra.fr \\ 2 Laval University, Quebec, Canada \\ bernard.moulin@ift.ulaval.ca \\ ${ }^{3}$ ENSFEA/INRA, UMR AGIR, Toulouse, France \\ laurent.bedoussac@inra.fr
}

\begin{abstract}
Although modeling argument structures is helpful to make involved parties understand the pros and cons of an issue and the context of each other's positions, stakeholders have no means to anticipate the impacts of adopting the debated solutions, let alone to compare them. This is where using simulation approaches would greatly enrich the deliberation process. This paper introduces an approach combining argumentation and simulation. We consider a case study in which both are used to assess and compare cultural options available to farmers.
\end{abstract}

\section{Introduction}

Making a decision involving several stakeholders with different objectives requires to take into account qualitative as well as quantitative information: the consequences of each possible decision, the stakeholders' viewpoints and preferences on the decisions, the parameters they considered as indicators. Among public policy decision problems, agri-food chain arbitrations involve various actors, from production to consumption through processing, distribution and recycling. Consequently, besides policy makers' scale, the interests of all the stakeholders of the chain interfere. Given the diversity of their viewpoints, they pursue possibly divergent objectives.

Although international research communities are active both in the argumentation and in the decision fields, most often these domains have been studied separately. [2] can be cited among the earliest formal attempts to combine both. Applications in agronomy have emerged a few years ago and are growing. Recent works have dealt with the interest of argumentation in decisions about agri-food chain steering $[6,13,14]$.

Within this context of argument-supported decision, this paper deals with the combination of qualitative and quantitative approaches. The qualitative model we consider is argumentation. The quantitative one is systems dynamics, which

(C) Springer International Publishing AG 2017

S. Benferhat et al. (Eds.): IEA/AIE 2017, Part II, LNAI 10351, pp. 275-281, 2017

DOI: $10.1007 / 978-3-319-60045-1 \_30$ 
allows scenario simulation. The difficult point concerns the connections between both formalisms, for which no results are available in the scientific literature. The advance of the proposed approach is to allow for testing the validity of an argument by simulating the scenario resulting from the decision this argument promotes. Therefore it provides a sound way of dealing with a weak point of argumentation in the literature, widely discussed but lacking of practical tools: argument strength evaluation $[1,5,6]$.

\section{Formalizing the Decision Problem}

Systems dynamics [7] is a mathematical modeling technique which allows analyzing the evolution over time of systems defined by a large number of interdependent variables. One of the variables considered by the system is thus time. We propose the following definition of the studied system.

Definition 1. The studied system is a set $X=\left\{t, x_{1}, \ldots, x_{n}\right\}$ of variables, where $t$ is time. A state of the system is described by an instantiation $V=$ $\left\{v_{t}, v_{1}, \ldots, v_{n}\right\}$ of $X$, where $v_{t}$ is the value of variable $t$ and for $i \in[1 ; n], v_{i}$ is the value of variable $x_{i}$.

We can distinguish three main categories of variables (apart from time):

- constants: their value does not vary over time. They are depicted by blackarrowed circles in the graphical model (see Fig. 1);

- stock variables: they represent the accumulation of a quantity over time and thus correspond to an integral-type function. They are represented as squares in the graphical model;

- the other variables (general case) are depicted by circles in the graphical model.

Definition 2. $X$ is partitioned in two subsets, $X_{\text {in }}$ and $X_{\text {out }}$. $X_{\text {in }}$ contains the variables whose initial value (in case of constants) or function definition (in case of other variables) can be chosen (or could be in hypothetical scenarios), since they have the meaning of controlled parameters of the system. $X_{\text {out }}$ contains the variables of the system on which there is no human control, thus their value is observed but not chosen. Therefore each variable $x_{i} \in X$ is a function of $X_{i n}$, denoted by $F_{i}$.

To grasp real-world decision schemes, with regard to previous works in multicriteria decision [4] and argumentation-based decision [2], we integrate within the system description a set of considered options (also called decisions or actions) and a set of considered goals. This yields the following framework:

Definition 3. A decision framework is a couple $\left(x_{o}, X_{G}\right)$ where:

- $x_{o} \in X_{i n}$ is the option variable. Its domain of values is denoted by $D_{o}$;

- $X_{G} \subseteq X_{\text {out }}$ is a set of goal variables, whose values are to be maximized. 
Decisional approaches of argumentation introduce a distinction between two types of arguments, those justifying beliefs, denoted epistemic arguments, and those justifying actions, denoted practical arguments [8]. In this study we are interested in the latter, on which less literature is available. A formalization is proposed in [2]. To be in accordance with previous works and take into account decision schemes [12], we will consider an argument as a triplet $<$ Option, Goal, Justification $>$. Thus an argument provides a justification for promoting an option in order to achieve a goal. This can be expressed in our framework by the following definition.

An argument is then defined as follows in our framework.

Definition 4. An argument a is a triplet $\left\langle o, x_{g}, J\right\rangle$, where:

- o $\in D_{o}$, the option promoted by the argument $a$, is the value chosen for the option variable $x_{o}$;

- $x_{g} \in X_{G}$ is the goal pursued by the argument $a$;

- $J$, the justification of the argument, is an instantiation of the set of variables $X_{i n} \backslash x_{o}$. It totally defines the state of the system by fixing the values $v_{i}$ of the variables $x_{i} \in X_{\text {in }} \backslash x_{o}$.

Once an argument defined, the next question is how to determine if it sound or not? The principle we propose is to verify if the value of the goal obtained with the settings defined by the argument is the best that would be obtained for any option with the same settings.

Definition 5. An argument $a=\left\langle o, x_{g}, J\right\rangle$ is sound if $F_{g}(J \cup\{o\})=$ $\max _{d \in D_{o}} F_{g}(J \cup\{d\})$.

\section{Running the Model on the Case Study}

In the context of decision support, our work aims at proposing a systematic approach to assess various options available to farmers for cereal-legume intercrops with respect to the corresponding sole crop alternatives. This comparison is possible when considering farmers' gross margin. We specifically address the case of intercropping of durum wheat and legumes.

Intercropping, the simultaneous growth of two or more species in the same field for a significant period, is an application of ecological principles. This practice is particularly suited in low nitrogen input systems where it optimizes the use of nitrogen resources through nitrogen fixation of legumes leading to improved and stabilized yields and increased cereal protein content [3]. Nevertheless, despite their numerous agronomic interests widely demonstrated, intercrops are only slightly adopted by farmers, except for animal feeding and/or in organic farming. Among the main reasons, their potential economic advantage remains questionable because it depends on many factors such as the difference between crop prices, the cost to efficiently separate the grains, but also the input prices and the amount of subsidies. A last issue concerns the way to evaluate the 
intercrop efficiency by comparing it to sole crops [3]. Indeed, the sole crop reference could be the best sole crop managed with inputs, or with the same amount of inputs as in intercrop, or the average efficiency of the two sole crops. Finally, considering or not the rotation usually leads to strongly different conclusions. A large number of arguments for and against cereal-legume intercropping have been expressed by the main actors of the supply chain [3,9-11].

Based both on literature review (in particular $[3,10,11]$ ) and on interviews with domain specialists, various arguments in favor and against cereal-legume intercrops were identified.

"Pro" arguments mainly mentioned:

- the improved soil fertility;

- the reduction of organic nitrogen fertilizers, expensive and unefficient;

- the higher protein content of harvested grain, a quality criterion for durum wheat:

- the better control of weeds;

- the better resistance against plant agressors;

- more stable yields despite climate variability.

"Con" arguments essentially concerned:

- the non-synchronized dates of sow and harvest for the two species;

- the variable composition of harvest;

- the specific sorting operation required;

- the lack of distribution and valorization networks;

- restricted marketing possibilities, due to the absence of a regulatory statute for cereal-legume intercrops;

- discouraging CAP aid policies.

The main indicator that interests us here to reflect the attractiveness of the cultural system for the farmer is the direct gross margin. We consider three value options for the culturalChoice variable: $\{$ soleCereal, soleLegume, intercrop $\}$, which respectively correspond to cereal monoculture, legume monoculture and ceral-legume intercrop. Let us examine two economic arguments.

1. The argument in favor of cereal-legume intercrops on the basis of reduced organic nitrogen fertilizers can be formalize as follows: $a_{1}=\left\langle o_{1}, x_{g} 1, J_{1}\right\rangle$ with $o_{1}=$ intercrop, $x_{g} 1=$ directGrossMargin, $J_{1}$ defined by: unchanged current values for the publicAids variable, adapted values for the nitrogenInput variable (20 nitrogen units economy per year for the intercrop, 40 for sole legume, 0 for sole cereal) and unchanged current values for the sorting Cost variable.

2. The argument in favor of sole cereal culture on the basis of avoided sorting operations can be formalize as follows: $a_{2}=\left\langle o_{2}, x_{q} 2, J_{2}\right\rangle$ with $o_{2}=$ soleCereal, $x_{g} 2=$ directGrossMargin, $J_{2}$ defined by: unchanged current values for the publicAids variable, unchanged current values for the nitrogenCost variable and decreased values (half-reduced) for the sortingCost variable. 
Table 1. Results for argument $a_{1}$

\begin{tabular}{l|l|l|l}
\hline & Sole cereal option & $\begin{array}{l}\text { Sole Legume } \\
\text { option }\end{array}$ & $\begin{array}{l}\text { Cereal-legume } \\
\text { intercrop option }\end{array}$ \\
\hline $\begin{array}{l}\text { Goal value (direct } \\
\text { gross margin in } \\
\text { euro/ha) }\end{array}$ & 977 & 788 & $\mathbf{5 0 1}$ \\
\hline
\end{tabular}

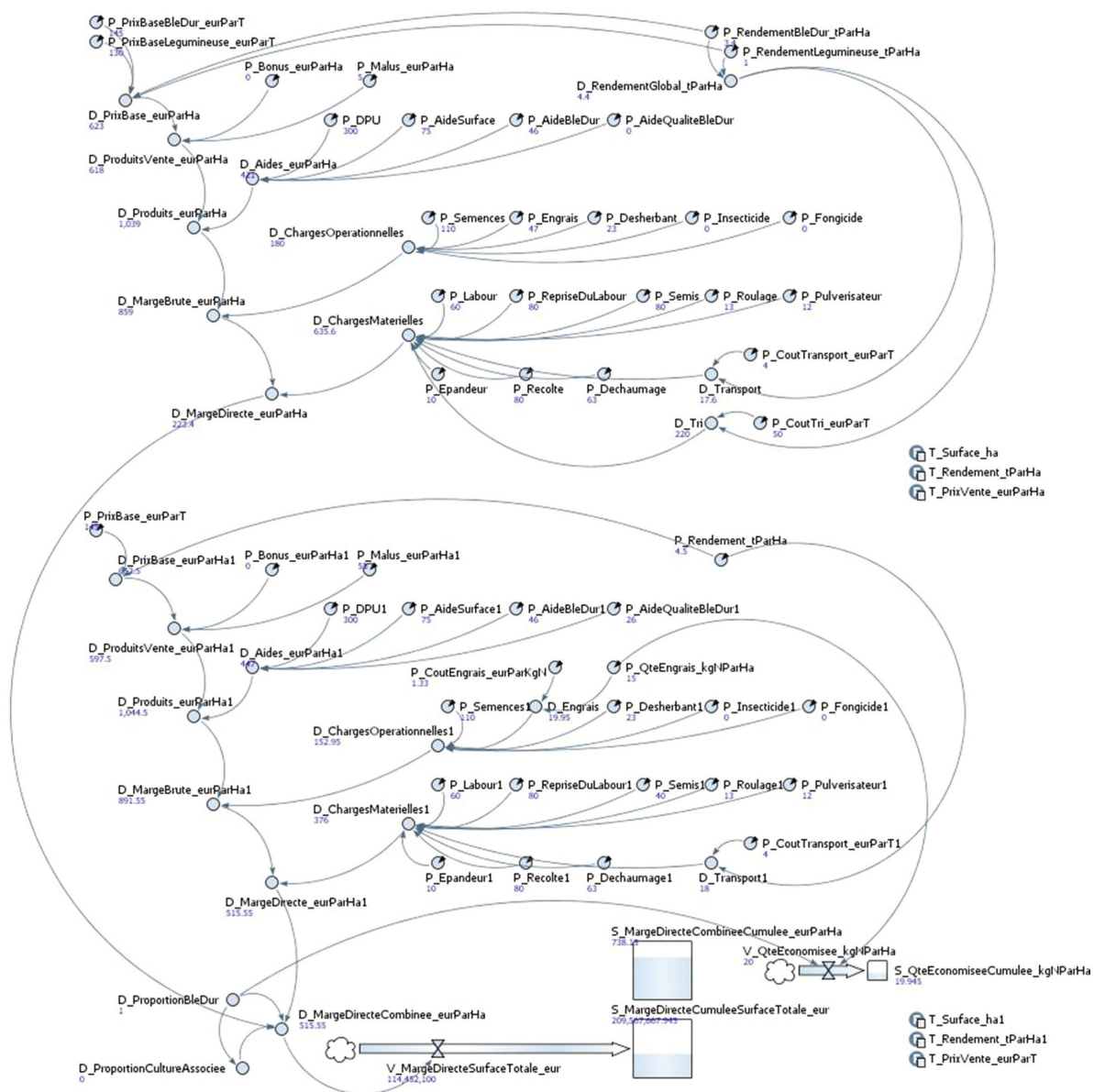

Fig. 1. The generic model run (Anylogic software)

The variable settings of argument $a_{1}$ and $a_{2}$ are run for the three options. The generic model used is shown in Fig. 1.

Argument $a_{1}$ and $a_{2}$ obtained the following results (Tables 1 and 2) for a 2-year simulation. 
Table 2. Results for argument $a_{2}$

\begin{tabular}{l|l|l|l}
\hline & Sole cereal option & Sole Legume option & $\begin{array}{l}\text { Cereal-legume } \\
\text { intercrop option }\end{array}$ \\
\hline $\begin{array}{l}\text { Goal value (direct gross } \\
\text { margin in euro/ha) }\end{array}$ & $\mathbf{9 7 7}$ & 788 & 721 \\
\hline
\end{tabular}

\section{Conclusion}

The goal value obtained for the option promoted by $a_{1}$ (cereal-legume intercrop) does not obtain the greatest goal value. On the contrary, the computed goal value for this option is the lowest one. Thus the argument $a_{1}$ is not validated. This simulation shows that higher nitrogen costs do not heavily penalize classical cereal cultures, although they do not benefit from nitrogen fixation by legumes. Of course to balance this conclusion, one must keep in mind that the simulation gives a partial view of the problem.

The goal value obtained for the option promoted by $a_{2}$ (sole cereal culture) obtains the greatest goal value. Thus the argument $a_{2}$ is validated. The simulation shows that sorting costs must be reduced by more than 2 for intercrops to be economivcally attractive. However the simulation also shows that, if this is possible in the future, then intercrops will become concurrential, since the goal value gap is highly reduced.

\section{References}

1. Amgoud, L., Cayrol, C.: A reasoning model based on the production of acceptable arguments. Ann. Math. Artif. Intell. 34, 197-216 (2002)

2. Amgoud, L., Prade, H.: Using arguments for making and explaining decisions. Artif. Intell. 173(3-4), 413-436 (2009)

3. Bedoussac, L., Journet, E.P., Hauggaard-Nielsen, H., Naudin, C., Corre-Hellou, G., Jensen, E.S., Prieur, L., Justes, E.: Ecological principles underlying the increase of productivity achieved by cereal-grain legume intercrops in organic farming. a review. Agron. Sustain. Dev. 35(3), 911-935 (2015)

4. Belton, V., Stewart, T.: Multiple Criteria Decision Analysis: An Integrated Approach. Springer, New York (2002)

5. Bench-Capon, T.J.M.: Persuasion in practical argument using value-based argumentation frameworks. J. Logic Comput. 13(3), 429-448 (2003)

6. Bourguet, J.R., Thomopoulos, R., Mugnier, M.L., Abécassis, J.: An artificial intelligence-based approach to deal with argumentation applied to food quality in a public health policy. Expert Syst. Appl. 40(11), 4539-4546 (2013)

7. Forrester, J.: Counterintuitive behavior of social systems. Tech. Rev. 73(3), 52-68 (1971)

8. Harman, G.: Practical aspects of theorical reasoning. In: Mele, A.R., Rawling, P. (eds.) The Oxford Handbook of Rationality, pp. 45-56. Oxford University Press, New York (2004) 
9. Magrini, M.B., Triboulet, P., Bedoussac, L.: Pratiques agricoles innovantes et logistique des coopératives agricoles. une étude ex-ante sur l'acceptabilité de cultures associées blé dur-légumineuses. Economie Rurale 338, 25-45 (2013)

10. Pelzer, E., Bedoussac, L., Corre-Hellou, G., Jeuffroy, M., Métivier, T., Naudin, C.: Association de cultures annuelles combinant une légumineuse et une céréale: retours d'expériences d'agriculteurs et analyse. Innovations Agronomiques 40, 73$91(2014)$

11. PerfCom Project: Les cultures associées céréale / légumineuse en agriculture "bas intrants" dans le sud de la france (2012). http://www6.montpellier.inra.fr/ systerra-perfcom

12. Savage, L.J.: The Foundations of Statistics, 2nd edn. Dover Pub., New York (1972)

13. Tamani, N., Mosse, P., Croitoru, M., Buche, P., Guillard, V., Guillaume, C., Gontard, N.: An argumentation system for eco-efficient packaging material selection. Comput. Electron. Agric. 113, 174-192 (2015)

14. Thomopoulos, R., Croitoru, M., Tamani, N.: Decision support for agri-food chains: a reverse engineering argumentation-based approach. Ecol. Inform. 26(2), 182-191 (2015) 